\title{
Saudi Radiologists' and Radiographers' Perceptions of Accreditation Programmes in Clinical Radiology Departments: A Cross-Sectional Study
}

\author{
Abdulaziz A Qurashi, Walaa M Alsharif (D) \\ Department of Diagnostic Radiology Technology, College of Applied Medical Sciences, Taibah University, Madinah, Saudi Arabia
}

Correspondence: Abdulaziz A Qurashi, Department of Diagnostic Radiology Technology, College of Applied Medical Sciences, Taibah University, Anadah Bin Umayyah Road, Taibah, Madinah, 42353, Saudi Arabia, Tel +966014 86I 8888 Ext. 3603, Email aaqurashi@taibahu.edu.sa

Purpose: The hospital accreditation programme is an assessment tool that involves a comprehensive evaluation by an external independent accreditation body to ensure consistency in clinical practice by adhering to the established standards and guidelines. The study aims to investigate Radiology prOfessionals' perceptions Of the impact Of accreditation and implementation of change towards the quality-of-service delivery in Radiology Departments.

Methods: A cross-sectional prospective study was conducted in Saudi Arabia among radiology professionals (ie, radiographers and radiologists) from July to September 2021. After obtaining institutional review board approval from the local ethics committee and using a non-probability convenient sampling technique, 335 participants completed the survey, which was distributed via social media channels, and through professional networks within hospitals across the country.

Results: A total of 335 participants agreed to participate. The study's participants strongly agreed that the accreditation programmes have positively impacted customer satisfaction and care provided to patients. A significant difference was identified in the level of agreement on the effect of accreditation programmes when hospital types and personnel qualifications were tested $(\mathrm{P}<0.05)$. Radiology personnel who worked in academic hospitals and who had diplomas and PhDs degrees showed a significantly higher level of agreement than other participants $(\mathrm{P}<0.05)$.

Conclusion: Saudi radiologists and radiographers showed strong agreement or agreement towards hospital accreditation programmes domains' criteria. The results of the study support the need to bridge the gap between higher-level management and employees in order to facilitate change and enhance the standards of quality and practice in radiology departments. Additional policies are needed to continue and strengthen quality improvement programmes.

Keywords: accreditation, quality, radiology, healthcare, radiology professionals

\section{Introduction}

The quality of healthcare services is an important aspect in any healthcare system schema. ${ }^{1}$ Patients always expect quality in healthcare service delivery, and this forces healthcare policymakers to make it a key priority. ${ }^{2}$ Several plans and strategies have been highlighted in the literature to facilitate healthcare service delivery improvement. Among these are total quality management, ${ }^{3}$ statistical process control, ${ }^{4}$ plan-do-study-act ${ }^{5}$ and Six Sigma. ${ }^{6}$ To support healthcare quality at service and organisational levels, Greenfield and Braithwaite (2009) referred to the use of an official accreditation programme, such as those devised by the Joint Commission International (JCI) and the Canadian Council on Health Services Accreditation (CCHSA). ${ }^{7}$ Accreditation programmes involve the certification of healthcare organisations and/or institutions via an approved external body to evaluate performance and establish standards in order to maintain continuous improvement. ${ }^{7,8}$

A study undertaken by the World Health Organization (WHO) in 2003 highlighted a lack of accreditation programmes at healthcare sites across the Eastern Mediterranean region, including Saudi Arabia (SA). ${ }^{9}$ Since then, accreditation programmes have been developed and implemented in healthcare organisations in SA making it 
a pioneer in this field among Arab countries. ${ }^{10}$ Furthermore, the Central Board for Accreditation of Healthcare Institutions (CBAHI) was established by the Saudi Ministry of Health in 2005. The CBAHI was formed to promote healthcare quality standards in its facilities across SA. Recently, CBAHI accreditation has become mandatory for all healthcare facilities operating (public and private) in SA. ${ }^{11}$

Over the last decade, there has been an increasing commitment across healthcare organisations in SA to become accredited by international bodies (ie the US-based JCI and the CCHSA). ${ }^{12}$ The rationale for this trend has been the promotion and enhancement of healthcare services provided to patients. ${ }^{13}$ Several studies targeting the nursing profession have examined the effect of accreditation programmes on the healthcare system in SA. ${ }^{10,14,15}$ It was indicated that accreditation programmes have improved nurses' knowledge about the quality of patient care in the Saudi system. ${ }^{14}$ Additional studies showed that engagement with accreditation processes has a positive effect on patient services, safety and allocation of internal resources to improve quality. ${ }^{10,15}$

Radiology departments endeavour to provide safe and high-quality services. ${ }^{16}$ Any healthcare system, including radiology departments, should fully understand its own service delivery and be able to address issues regarding the services provided and how these are delivered. This may not be achieved without a systematic approach to assess current practices and maintain high-quality service delivery. ${ }^{17}$ Therefore, an accreditation programme is important to ensure consistency in radiology clinical practice by adhering to the established standards and guidelines. ${ }^{18}$ Hogan et al outlined the importance of involving healthcare professionals (eg radiologists and radiographers) working within a unit in quality improvement processes because they can best understand the actual problems arising from clinical incidents within that unit. ${ }^{19}$ The value of involving radiographers in quality improvement processes to improve patient care by reducing unnecessary examinations and maintaining compliance was also noted.$^{20}$ In addition, radiologists and radiographers play an important role in evaluating the level of compliance in clinical practice (eg images and equipment) against a set of established standards. ${ }^{21}$

Despite the predominance of this practice, there is still no published research regarding the value, from a specific outcome perspective, of engaging with international accreditation organisations and/or national accreditation in diagnostic imaging departments. Therefore, the aim of this study was to investigate the impact of the accreditation programme on radiography professionals' (radiologists and radiographers) perceptions and implementation of change to the quality of service delivery in radiology departments.

\section{Methodology}

\section{Ethical Consideration}

This study aimed to collect data from a sample across the Kingdom of Saudi Arabia (KSA), after obtaining an ethical approval from the institutional review board of the College of Applied Medical Science at Taibah University, Madinah city, Western Region, KSA (Reference Number: 2021/99/319/DRD). Participation in this study was voluntary, and informed consent was obtained. All methods were carried out in accordance with relevant guidelines and regulations.

\section{Study Design and Participants}

A cross-sectional quantitative questionnaire study design was implemented. According to the statistics described in the Ministry of Human Resources and Social Development, ${ }^{22}$ and out of the 7436 radiology professionals (Radiologists: $\mathrm{n}=2767$, Radiographers: $n=4669$ ); a representative sample of 335 (Radiologists: $n=64$, Radiographers: $n=271$ ) completed the survey. This study implemented a non-probability convenient sampling technique and the sample size was calculated through Raosoft online tool. ${ }^{23,24}$

An online questionnaire was distributed among radiology professionals via email, social media channels and through professional networks within hospitals across the country. The study instrument was adapted from El-Jardali et al study, ${ }^{25}$ and was modified and tailored to ensure its current suitability to the participants' field of study. The tailored questionnaire was validated by a panel of experts consisting of five senior radiologists, and five senior radiographers to ensure that each question was clearly stated, easy to read and currently suitable. Informed consent agreement was granted after the participants were provided with requirements, aims, and the information about the study's confidentiality. The survey was 
presented to participants in both Arabic and English. The questionnaire comprised closed-ended questions. Demographic background information including gender, age, type of hospital, qualifications and occupation/position was obtained. The tailored questionnaire contained 25 questions covering the following six domains: (a) Quality results (3 questions); (b) Leadership, commitment and support (4 questions); (c) Strategic quality planning (5 questions); (d) Human resources utilisation (3 questions); (e) Staff involvement in accreditation (4 questions); and (f) Benefits of accreditation (6 questions). ${ }^{26}$ A 5-point Likert scale was used to indicate the agreement level among participants, with a score of one representing strong agreement.

\section{Data Analysis}

Data on Likert scale were analysed using IBM SPSS version 25 , and a p-value $<0.05$ was considered statistically significant. Frequencies and percentages of sociodemographic variables were calculated. Mean and standard deviation (SD) were calculated for the level of agreement among radiology personnel. A Kruskal-Wallis test was used to examine the level of agreement between sociodemographic variables. Association between variables was calculated by using Spearman correlation.

\section{Results}

The numerical data for radiology personnel demographics is listed in Table 1 and illustrated in Figure 1A-D. A total of 426 radiology personnel agreed to participate in this study. However, only 335 questionnaires were completed by radiology personnel, and 91 incomplete questionnaires were excluded from the study.

Findings were analysed to determine the level of agreement among radiology personnel across SA concerning the implementation of change and accreditation effect on the quality-of-service delivery in radiology departments. Tables 2 illustrates the combined responses of the participants across all domains. For domain one, the participants strongly agreed that the accreditation programme positively impacted customers' satisfaction and patient care. The results also showed a similar level of agreement among participants in relation to the impact of the accreditation programme on the other five domains. In addition, the participants were in agreement that the continuation of the accreditation programme would improve the quality-of-service delivery in radiology departments across the country.

A review of the data showed that no significant difference was found between the level of agreement among the study participants based on their qualifications and occupations across domains 1-3 (P > 0.05) (Table 3). There was also no significant difference noted in the level of agreement among the participants based on their occupations in domains 4 and $5(\mathrm{P}>0.05)($ Table 3).

Table I Demographic Characteristics of Study Sample

\begin{tabular}{|l|c|c|c|c|c|c|c|c|}
\hline \multirow{2}{*}{ Profession } & \multicolumn{4}{|c|}{ Hospital Types } & \multicolumn{3}{c|}{ Qualifications } \\
\cline { 2 - 9 } & Public & $\begin{array}{c}\text { Semi- } \\
\text { Public }\end{array}$ & Private & Academic & Diploma & BSc & MSc & PhD \\
\hline Head of Radiology Department & $9(7.7 \%)$ & $4(3.3 \%)$ & $2(2.7 \%)$ & $2(8.7 \%)$ & - & - & $6(9.8 \%)$ & $11(34.4 \%)$ \\
\hline Chief of Radiographers & $8(6.8 \%)$ & $13(10.7 \%)$ & $3(4.1 \%)$ & $2(8.7 \%)$ & $6(14.6 \%)$ & $6(3 \%)$ & $10(16.4 \%)$ & $4(12.5 \%)$ \\
\hline Radiologists & $22(18.8 \%)$ & $12(9.9 \%)$ & $9(12.2 \%)$ & $4(17.4 \%)$ & - & $30(14.9 \%)$ & $5(8.2 \%)$ & $12(37.5 \%)$ \\
\hline Radiographers (Supervisor) & $14(12 \%)$ & $15(12.4 \%)$ & $7(9.5 \%)$ & $4(17.4 \%)$ & - & $16(8 \%)$ & $22(36.1 \%)$ & $2(6.3 \%)$ \\
\hline Radiographers (Staff) & $64(54.7 \%)$ & $77(63.7 \%)$ & $53(71.5 \%)$ & $11(47.8 \%)$ & $35(85.4 \%)$ & $149(74.1 \%)$ & $18(29.5 \%)$ & $3(9.4 \%)$ \\
\hline Total & $117(34.9 \%)$ & $121(36.1 \%)$ & $74(22.1 \%)$ & $23(6.9 \%)$ & $41(12.2 \%)$ & $201(60 \%)$ & $61(18.2 \%)$ & $32(9.6 \%)$ \\
\cline { 2 - 9 } & & & & & 335 \\
\hline
\end{tabular}

Notes: Qualification: Diplomat (2 years of post high school education+ one year internship in radiological science), BSc (4 years+ one year internship in radiological science), MSc (Post BSc education in radiological science), PhD (Post MSc education in radiological science). Profession: Radiologists (Medical doctor who completed a radiology residency program and board exam), Radiographers (Diplomat, BSc, MSc or PhD holder with valid registration from local authority). 
A

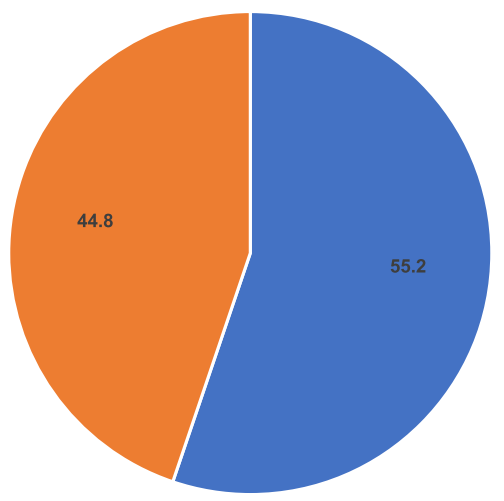

- Male - Female

Qualification

C

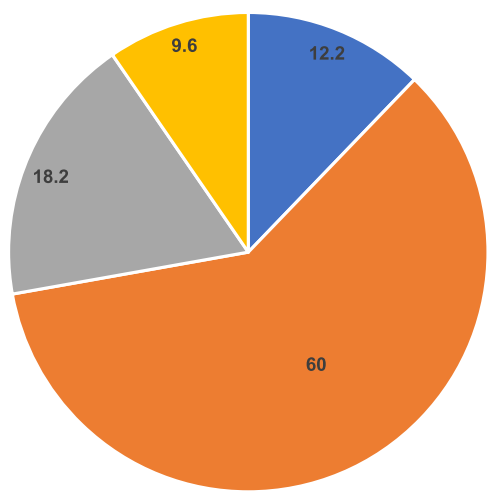

B Type of Hospitals

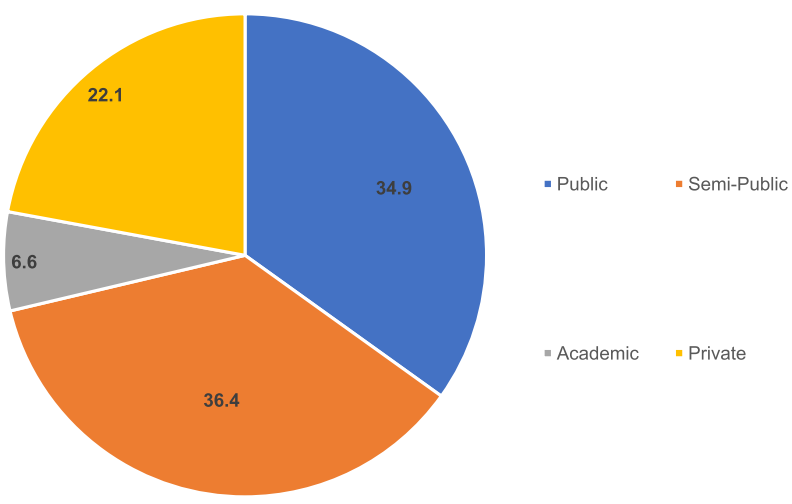

Occupation

D

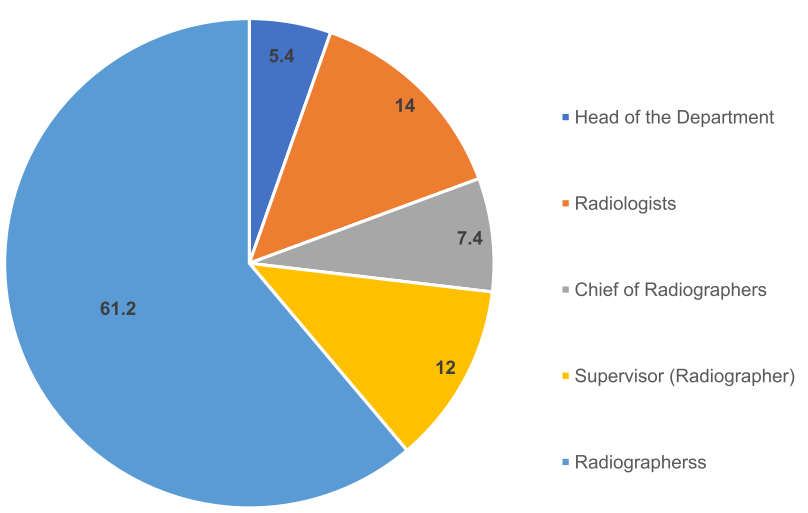

Figure I Sociodemographic information (A: percentage of participants based on their gender, B: percentage of participants based on their place of work, C: percentage of participants based on their academic qualifications, D: percentage of participants based on their occupation/position).

In contrast, a significant difference was identified between the level of agreement concerning the effect of accreditation programmes across all domains and hospital types $(\mathrm{P}<0.05)$ (Table 3$)$. Radiology personnel, who work in semipublic hospitals, showed a lower level of agreement than their equivalent in other hospitals. A significant difference was found between the level of agreement among the participants based on their qualifications in domains 3-6 (P $<0.05$ ) (Table 3). Those with diplomas and PhDs expressed a higher level of agreement than other participants. In addition, a significant difference in the level of agreement on the benefit of the accreditation programme among the radiology personnel was apparent based on their occupation $(\mathrm{P}<0.05)$ (Table 3). Radiologists showed a higher level of agreement than the other participants (Mean $=2.4, \mathrm{SD}=0.82$ ). Table 4 shows moderate positive correlation between domains.

\section{Discussion}

In the current study, the perception of accreditation was measured by six main domains: quality results, leadership, commitment and support, strategic quality planning, human resources utilisation, staff involvement in accreditation, and benefits of accreditation. To the best of our knowledge, this is the first study to examine perceptions of accreditation programmes among radiography professionals in Saudi Arabia. Foremost among the findings arising from this study is that an overall positive attitude to accreditation was shown by participants. Furthermore, participants strongly agreed that the accreditation programme positively impacted on the improvement of patient healthcare. Unsurprisingly, this has been achieved due to the great stress on the importance of applying such measures in the country by the governing body. Similar findings were shown in most published research in this context. ${ }^{12}$ 
Table 2 Radiology Personnel's Level of Agreement Concerning

\begin{tabular}{|c|c|c|c|c|c|c|c|c|}
\hline \multirow[t]{2}{*}{$\begin{array}{l}\text { Question } \\
\text { Number }\end{array}$} & \multirow[t]{2}{*}{ Factors } & $\begin{array}{l}\text { Strongly } \\
\text { Disagree }\end{array}$ & Disagree & Undecided & Agree & $\begin{array}{l}\text { Strongly } \\
\text { Agree }\end{array}$ & $\begin{array}{l}\text { Mean } \\
(\mathbf{S D})\end{array}$ & \multirow[t]{2}{*}{$\begin{array}{l}\text { Level of } \\
\text { Agreement }\end{array}$} \\
\hline & & \multicolumn{6}{|c|}{$\mathbf{N}(\%)$} & \\
\hline \multicolumn{9}{|c|}{ Domain I: Quality results (The impact of accreditation on the quality of results in radiology departments) } \\
\hline $\mathbf{I}$ & There is a measurable and steady improvement in the customer satisfaction. & $3(1)$ & $15(4.5)$ & $17(5)$ & $152(45)$ & $148(44)$ & $1.7(0.82)$ & $\begin{array}{l}\text { Strongly } \\
\text { Agree }\end{array}$ \\
\hline 2 & $\begin{array}{l}\text { There is a measurable and steady improvement in the quality of patient care provision } \\
\text { (eg infection control, professional communication, correct examination). }\end{array}$ & $2(1)$ & $12(3.6)$ & $23(7)$ & $145(43)$ & $153(46)$ & $1.7(0.79)$ & $\begin{array}{l}\text { Strongly } \\
\text { Agree }\end{array}$ \\
\hline 3 & $\begin{array}{l}\text { High-quality healthcare services have been maintained despite any constraints (eg } \\
\text { financial, training opportunities). }\end{array}$ & $5(1.5)$ & $20(6)$ & $33(10)$ & $146(44)$ & $131(39)$ & $1.9(0.92)$ & Agree \\
\hline \multicolumn{9}{|c|}{ Domain 2: The impact of accreditation on leadership, commitment and support in radiology departments } \\
\hline 4 & Maintaining quality improvements was supported by highly visible leadership. & $8(3)$ & $24(7)$ & $22(6.6)$ & $169(50)$ & $112(33)$ & $1.95(0.94)$ & Agree \\
\hline 5 & $\begin{array}{l}\text { The department's management allocates required resources (eg equipment, people, } \\
\text { finances, time) to improve quality. }\end{array}$ & $7(2)$ & $25(8)$ & $52(16)$ & $152(45)$ & 99 (30) & $2(0.96)$ & Agree \\
\hline 6 & $\begin{array}{l}\text { Quality of care and services improvement was in the high-yield activities for the } \\
\text { department's management. }\end{array}$ & $5(2)$ & $26(8)$ & $4 I(12)$ & $162(48)$ & $101(30)$ & $2(0.93)$ & Agree \\
\hline 7 & $\begin{array}{l}\text { A clear vision for improving the quality of care and services has been articulated by the } \\
\text { department's management. }\end{array}$ & $7(2)$ & $36(\mathrm{II})$ & $29(9)$ & $\mid 70(5 \mid)$ & $93(28)$ & $2(0.98)$ & Agree \\
\hline \multicolumn{9}{|c|}{ Domain 3: The impact of accreditation on strategic quality planning in radiology departments } \\
\hline 8 & $\begin{array}{l}\text { Based on recommendations from accreditation audits, adequate time is given to } \\
\text { radiology personnel to plan for and test quality improvement opportunities. }\end{array}$ & $8(2)$ & $4 I(12)$ & $42(13)$ & $150(45)$ & $94(28)$ & $2(1.04)$ & Agree \\
\hline 9 & $\begin{array}{l}\text { Radiology personnel contribute in plan development for quality improvement in your } \\
\text { department. }\end{array}$ & $9(3)$ & $34(10)$ & $39(12)$ & $166(50)$ & $87(26)$ & $2(1)$ & Agree \\
\hline 10 & $\begin{array}{l}\text { Prioritising quality improvement requirement is one of the key roles played by middle } \\
\text { managers (eg Chief of Radiographers and/or Technical Directors and Supervisors). }\end{array}$ & $3(1)$ & $17(5)$ & $50(15)$ & $165(49)$ & $100(30)$ & $1.9(0.85)$ & Agree \\
\hline II & $\begin{array}{l}\text { The quality of services expected by patients is essential in deciding on quality } \\
\text { improvement priorities. }\end{array}$ & $5(2)$ & $18(5)$ & $32(10)$ & $|8|(54)$ & $99(30)$ & $1.95(0.86)$ & Agree \\
\hline 12 & $\begin{array}{l}\text { A key role is played by radiology personnel in setting priorities for quality } \\
\text { improvement through representation in the department's organisational chart. }\end{array}$ & 7 (2) & $27(8)$ & $4 I(12)$ & 161 (48) & $99(30)$ & $2(0.96)$ & Agree \\
\hline
\end{tabular}


Table 2 (Continued).

\begin{tabular}{|c|c|c|c|c|c|c|c|c|}
\hline \multirow[t]{2}{*}{$\begin{array}{l}\text { Question } \\
\text { Number }\end{array}$} & \multirow[t]{2}{*}{ Factors } & $\begin{array}{l}\text { Strongly } \\
\text { Disagree }\end{array}$ & Disagree & Undecided & Agree & $\begin{array}{l}\text { Strongly } \\
\text { Agree }\end{array}$ & $\begin{array}{l}\text { Mean } \\
\text { (SD) }\end{array}$ & \multirow[t]{2}{*}{$\begin{array}{l}\text { Level of } \\
\text { Agreement }\end{array}$} \\
\hline & & \multicolumn{6}{|c|}{$\mathbf{N}(\%)$} & \\
\hline \multicolumn{9}{|c|}{ Domain 4: The impact of accreditation on human resources in radiology departments } \\
\hline 13 & Training and continuous education are provided to radiology personnel. & $13(4)$ & $38(\mathrm{II})$ & $46(14)$ & $150(45)$ & $88(26)$ & $2.2(1.07)$ & Agree \\
\hline 14 & $\begin{array}{l}\text { Radiology personnel are acknowledged (eg financially, verbally, etc.) for their } \\
\text { performance in improving quality. }\end{array}$ & $31(10)$ & $39(12)$ & $60(18)$ & $135(40)$ & $70(21)$ & $2.4(1.2)$ & Agree \\
\hline 15 & $\begin{array}{l}\text { The radiology department has an effective system for radiology personnel to make } \\
\text { suggestions to management on how to improve quality. }\end{array}$ & $19(6)$ & $34(10)$ & $40(12)$ & $161(48)$ & $81(24)$ & $2.2(1.10)$ & Agree \\
\hline \multicolumn{9}{|c|}{ Domain 5: the staff involvement in accreditation within radiology departments } \\
\hline 16 & $\begin{array}{l}\text { Following the last cycle of accreditation review, the radiology department management } \\
\text { implemented required changes. }\end{array}$ & $9(3)$ & $20(6)$ & $53(16)$ & $162(48)$ & $91(27)$ & $2(0.95)$ & Agree \\
\hline 17 & $\begin{array}{l}\text { There was participation in the implementation of these changes in the radiology } \\
\text { department. }\end{array}$ & $10(3)$ & $26(8)$ & $58(17)$ & $148(44)$ & $93(28)$ & $2.1(1)$ & Agree \\
\hline 18 & $\begin{array}{l}\text { The recommendations made to the radiology department since the last survey by the } \\
\text { accreditation team were helpful. }\end{array}$ & $6(2)$ & $23(7)$ & $56(17)$ & $159(48)$ & $91(27)$ & $2(0.93)$ & Agree \\
\hline 19 & $\begin{array}{l}\text { The recommendations given by the accreditation team and/or auditors were helpful in } \\
\text { improving radiology personnel skills/knowledge. }\end{array}$ & $4(1)$ & $29(9)$ & $56(17)$ & $157(47)$ & $89(27)$ & $2(0.9)$ & Agree \\
\hline \multicolumn{9}{|c|}{ Domain 6: The benefits of accreditation in radiology departments } \\
\hline 20 & Accreditation improves patient care in the radiology department. & $4(1)$ & $16(5)$ & $40(12)$ & $165(49)$ & $110(33)$ & $1.9(0.86)$ & Agree \\
\hline 21 & $\begin{array}{l}\text { Accreditation facilitates teamwork and collaboration encouragement and staff } \\
\text { motivation. }\end{array}$ & $8(2)$ & $21(6)$ & $68(20)$ & $147(44)$ & $91(27)$ & $2.1(0.96)$ & Agree \\
\hline 22 & $\begin{array}{l}\text { A better use of resources (ie finances, people, time and equipment) were enabled } \\
\text { following accreditation. }\end{array}$ & $9(3)$ & $25(8)$ & $63(19)$ & I52 (45) & $86(26)$ & $2.1(0.98)$ & Agree \\
\hline 23 & $\begin{array}{l}\text { Collaboration with other healthcare partners (other hospitals, diverse hospitals, } \\
\text { private clinics, etc.) was achieved following accreditation. }\end{array}$ & $8(2.4)$ & $21(6.3)$ & $72(21.5)$ & I $36(4 \mid)$ & 98 (29) & $2.1(0.98)$ & Agree \\
\hline 24 & $\begin{array}{l}\text { A local accreditation programme is a valuable tool to improve service delivery within } \\
\text { the radiology department. }\end{array}$ & 7 (2) & $26(8)$ & $56(17)$ & I 36 (4I) & IIO (33) & $2(0.99)$ & Agree \\
\hline 25 & $\begin{array}{l}\text { An international accreditation programme is a valuable tool to improve service } \\
\text { delivery within the radiology department. }\end{array}$ & $7(2)$ & $12(4)$ & $53(16)$ & I56 (47) & $107(32)$ & I.87 (0.9) & Agree \\
\hline
\end{tabular}


Table 3 Comparison of All Domains According to the Sociodemographic Variables

\begin{tabular}{|c|c|c|c|c|c|c|c|c|c|c|c|c|c|}
\hline & \multicolumn{13}{|c|}{ Domain I: Quality Results (The Impact of Accreditation on the Quality of Results in Radiology Departments) } \\
\hline & \multicolumn{4}{|c|}{ Hospital Type } & \multicolumn{4}{|c|}{ Qualification } & \multicolumn{5}{|c|}{ Occupation } \\
\hline & Public & Semi-public & Academic & Private & Dip & BSc & MSc & PhD & Head of department & Radiologists & Chief of radiographers & $\begin{array}{c}\text { Radiographer } \\
\text { (Supervisor) }\end{array}$ & Radiographers \\
\hline Mean & 1.82 & 1.61 & 2.15 & 1.83 & 1.9 & 1.75 & 1.65 & 1.91 & 1.46 & 1.91 & 1.66 & 1.70 & 1.78 \\
\hline SD & 0.79 & 0.63 & 0.63 & 0.75 & 0.78 & 0.69 & 0.68 & 0.95 & 0.41 & 0.90 & 0.76 & 0.75 & 0.69 \\
\hline \multirow[t]{2}{*}{$P$ value } & \multicolumn{4}{|c|}{0.002} & \multicolumn{4}{|c|}{0.22} & \multicolumn{5}{|c|}{0.21} \\
\hline & \multicolumn{13}{|c|}{ Domain 2: The impact of accreditation on leadership, commitment and support in radiology departments } \\
\hline Mean & 2.11 & 1.82 & 2.26 & 2.17 & 2.21 & 2.02 & 1.88 & 2.12 & 1.65 & 2.16 & 1.81 & 2.03 & 2.05 \\
\hline SD & 0.93 & 0.67 & 0.74 & 8.13 & 0.74 & 0.80 & 0.79 & 1.04 & 0.79 & 0.89 & 0.61 & 0.92 & 0.79 \\
\hline \multirow[t]{2}{*}{$P$ value } & \multicolumn{4}{|c|}{0.001} & \multicolumn{4}{|c|}{0.20} & \multicolumn{5}{|c|}{0.108} \\
\hline & \multicolumn{13}{|c|}{ Domain 3: The impact of accreditation on strategic quality planning in radiology departments } \\
\hline Mean & 2.14 & 1.85 & 2.32 & 2.15 & 2.28 & 2.01 & 1.95 & 2.21 & 1.66 & 2.25 & 2.04 & 2.12 & 2.03 \\
\hline SD & 0.87 & 0.66 & 0.63 & 0.79 & 0.77 & 0.79 & 0.74 & 0.76 & 0.48 & 0.77 & 0.52 & 0.90 & 0.79 \\
\hline \multirow[t]{2}{*}{$P$ value } & \multicolumn{4}{|c|}{0.001} & \multicolumn{4}{|c|}{0.1} & \multicolumn{5}{|c|}{0.09} \\
\hline & \multicolumn{13}{|c|}{ Domain 4: The impact of accreditation on human resources in radiology departments } \\
\hline Mean & 2.53 & 2.02 & 2.85 & 2.30 & 2.56 & 2.26 & 2.15 & 2.65 & 2.07 & 2.42 & 2.29 & 2.25 & 2.32 \\
\hline SD & 1.16 & 0.87 & 0.91 & 0.91 & 1.04 & 1.02 & 0.95 & 1.03 & 0.81 & 0.87 & 0.69 & 1.09 & 1.08 \\
\hline \multirow[t]{2}{*}{$P$ value } & \multicolumn{4}{|c|}{0.001} & \multicolumn{4}{|c|}{0.041} & \multicolumn{5}{|c|}{0.78} \\
\hline & \multicolumn{13}{|c|}{ Domain 5: The staff involvement in accreditation within radiology departments } \\
\hline Mean & 2.17 & 1.91 & 2.15 & 2.31 & 2.41 & 2.01 & 2.13 & 2.27 & 1.77 & 2.28 & 2.23 & 2 & 2.1 \\
\hline SD & 0.95 & 0.71 & 0.61 & 0.75 & 0.85 & 0.81 & 0.77 & 0.82 & 0.51 & 0.76 & 0.66 & 0.79 & 0.86 \\
\hline \multirow[t]{2}{*}{$P$ value } & \multicolumn{4}{|c|}{0.001} & \multicolumn{4}{|c|}{0.02} & \multicolumn{5}{|l|}{0.17} \\
\hline & \multicolumn{13}{|c|}{ Domain 6: The benefits of accreditation in radiology departments } \\
\hline Mean & 2.13 & 1.85 & 2.25 & 2.21 & 2.36 & 1.98 & 2.01 & 2.25 & 1.78 & 2.4 & 2.16 & 2.05 & 1.99 \\
\hline SD & 0.91 & 0.71 & 0.79 & 0.71 & 0.75 & 0.80 & 0.76 & 0.80 & 0.52 & 0.82 & 0.63 & 0.86 & 0.80 \\
\hline$P$ value & & 0.0 & & & & & 02 & & & & 0.014 & & \\
\hline
\end{tabular}


Table 4 Correlation Matrix Between Domains

\begin{tabular}{|c|c|c|c|c|c|c|c|}
\hline & & Domain I & Domain 2 & Domain 3 & Domain 4 & Domain 5 & Domain 6 \\
\hline \multirow[t]{2}{*}{ Domain I } & Correlation Coefficient & 1 & 0.665 & 0.603 & 0.581 & 0.557 & 0.550 \\
\hline & $P$ value & & 0.001 & 0.001 & 0.001 & 0.001 & 0.001 \\
\hline \multirow[t]{2}{*}{ Domain 2} & Correlation Coefficient & 0.665 & 1 & 0.730 & 0.695 & 0.633 & 0.657 \\
\hline & P value & 0.001 & & 0.001 & 0.001 & 0.001 & 0.001 \\
\hline \multirow[t]{2}{*}{ Domain 3} & Correlation Coefficient & 0.603 & 0.730 & 1 & 0.737 & 0.711 & 0.708 \\
\hline & P value & 0.001 & 0.001 & & 0.001 & 0.001 & 0.001 \\
\hline \multirow[t]{2}{*}{ Domain 4} & Correlation Coefficient & 0.581 & 0.695 & 0.737 & 1 & 0.720 & 0.702 \\
\hline & P value & 0.001 & 0.001 & 0.001 & & 0.001 & 0.001 \\
\hline \multirow[t]{2}{*}{ Domain 5} & Correlation Coefficient & 0.557 & 0.633 & 0.711 & 0.720 & 1 & 0.728 \\
\hline & $P$ value & 0.001 & 0.001 & 0.001 & 0.001 & & 0.001 \\
\hline \multirow[t]{2}{*}{ Domain 6} & Correlation Coefficient & 0.550 & 0.657 & 0.708 & 0.702 & 0.728 & 1 \\
\hline & $P$ value & 0.001 & 0.001 & 0.001 & 0.001 & 0.001 & \\
\hline
\end{tabular}

A study conducted by Algahtani et al found that the hospital accreditation programme had a positive effect on healthcare services in Saudi. ${ }^{27}$ Although most participants in the current study agreed that accreditation is a valuable tool to improve the quality of healthcare service delivery on both a local and international basis, $16 \%$ (Table 2) disagreed with this statement. A potential reason for this disagreement could be that participants may perceive accreditation programmes to be a heavy burden due to the large amount of paperwork required to document their contributions to these processes. ${ }^{28,29}$ A contrasting perspective was indicated by El-Jardali (2014), who stated that accreditation programmes have positive effects on staff motivation by involving them in decision-making and providing opportunities for professional development. ${ }^{26}$ Evidence shows that the availability of a culture that supports quality implementation and an approach that encourages flexible ways of implementing change are more important than meeting certain definitional criteria by an organisation. ${ }^{30}$ The findings of a different study also suggest that hospitals using a prospector-like approach, emphasising empowerment, decentralised control, "just-in-time" training and flexibility, are more likely to be successful in their implementation efforts than hospitals that emphasise more centralised control, stick with fairly traditional approaches to quality improvement work, and focus more on single departments or areas of activity. ${ }^{30}$

The literature has shown a significant association between continuous monitoring and tracking of improvement progress, measuring performance and providing evidence for compliance with accreditation standards. ${ }^{26}$ However, a disagreement to this statement was shown by $10 \%$ of the participants (Table 2), which may give the impression that there is a lack of continuous monitoring of the work and level of quality after gaining accreditation. This might imply that quality performance of radiology departments could fall back following the accreditation event due to work habits. ${ }^{31}$ It could be inferred from this that radiology professionals may see an accreditation programme as a mandatory process to be completed rather than an important tool for continuous improvement. Consequently, this may have a negative effect on the quality of service delivery, and may result in the momentum of continuous improvement not being embedded in clinical practice. The literature suggests that continuous monitoring of organisations is one of the most highly effective tools in an accreditation process. ${ }^{28}$

Continuous education and training programmes are important aspects to improve accreditation processes. Canadian healthcare organisations have undertaken similar measures pursuant to the accreditation process, including leadership training courses, benchmarking, patient surveys, audits, and incident reporting systems. ${ }^{28}$ Other studies agreed that continuous education in methods that supported quality improvement was crucial to improve job skills and 
performance. ${ }^{32-34}$ Such measures could be useful if applied to any healthcare organisation in SA as in the current study, $14 \%$ of study participants (Table 2) were dissatisfied with the education and training opportunities that enhance quality improvement and develop job skills and performance. This was similarly reported in a recent study conducted by Reisi et al who found that proper training and education had a positive impact on the quality of results. ${ }^{35}$

Although several studies have showed that acknowledgment of staff performance can have a positive impact on staff performance, satisfaction, and retention, ${ }^{36,37} 22 \%$ of the study participants (Table 2) agreed that there is a lack of recognition and motivation for their performance in obtaining accreditation. In similar studies, acknowledgment of staff performance had the lowest agreement score when participants were asked whether or not they were rewarded and recognised for improving quality. ${ }^{26,35}$ Therefore, department managers should support their employees and show recognition as this can be helpful to achieving the objectives of the organisation. Moreover, the literature suggests that employees' willingness of performing quality improvement activities is remarkably correlated with the culture of hospitals along with the degree of rewards and recognition..$^{30,34}$

The current study showed that the highest level of agreement concerning the effect of accreditation programmes was shown by those working in academic hospitals (Table 3). A reasonable explanation for this finding has to do with the bureaucratic system that tends to be applied in public hospitals. In addition to this, the culture within a particular hospital/ department could influence how professionals perceive the role of an accreditation programme in promoting and enhancing healthcare services. Health science academic programmes including radiology undergo a separate academic accreditation process, which includes several criteria of which clinically related criteria are pursued, which could potentially increase accreditation programmes' familiarity in academic hospitals and therefore may influence the level of agreement among academic radiology personnel. Furthermore, the literature suggests that using a prospector approach may be particularly challenging for hospitals traditionally operating under more centralised government auspices. ${ }^{30}$ It was also found that implementing quality improvement work in hospitals with a more bureaucratic system was a difficult task. ${ }^{30}$ A suggested solution to this issue is to improve communication between managers and employees during organisational change. ${ }^{26}$

\section{Limitations}

This study was designed to investigate radiology professionals' perceptions of the impact of accreditation on the qualityof-service delivery in radiology departments across Saudi Arabia. Therefore, the results should be treated with caution as they cannot be generalised to other countries. Since the panel of respondents was dominated by radiographers $(n=270)$ compared to radiologists $(n=47)$, the findings of comparison between the level of agreement between the two occupations should be interpreted with caution. Another limitation of this study is the lack of research published that focuses on the field of radiology, and this may cause difficulties in relating the results to other studies.

\section{Conclusion}

Saudi radiologists and radiographers showed strong agreement or agreement towards hospital accreditation programme domains' criteria. Although an overall positive attitude toward the impact of accreditation on quality of services delivery in radiology departments was shown, the opposite attitude was noted by some of the study participants. A disagreement was shown by a few participants about the continuous monitoring of the work and level of quality after gaining accreditation. In addition, some participants were dissatisfied with the current education and training opportunities that support quality improvement and develop performance and job skills. The current study showed that continuous quality improvement, strategic assessment and staff recognition are necessary to sustain the standards of quality in radiology departments. The results of the study support the need to bridge the gap between higher-level management and employees in order to facilitate change and enhance the standards of quality and practice in radiology departments. Additionally, additional policies are needed to continue and strengthen quality improvement programmes.

\section{Disclosure}

The authors report no conflicts of interest in this work. 


\section{References}

1. Abo-Hamad W, Arisha A. Simulation-optimisation methods in supply chain applications: a review. Irish J Manage. 2011;30(2):95.

2. Mosadeghrad AM. Factors influencing healthcare service quality. Int J Health Policy Manage. 2014;3(2):77. doi:10.15171/ijhpm.2014.65

3. McLaughlin CP, Kaluzny AD. Continuous Quality Improvement in Health Care: Theory, Implementation, and Applications. 2nd ed. Sudbury: Jones \& Bartlett Learning; 2004.

4. Thor J, Lundberg J, Ask J, et al. Application of statistical process control in healthcare improvement: systematic review. BMJ Qual Saf. 2007;16 (5):387-399. doi:10.1136/qshc.2006.022194

5. Taylor MJ, McNicholas C, Nicolay C, Darzi A, Bell D, Reed JE. Systematic review of the application of the plan-do-study-act method to improve quality in healthcare. BMJ Qual Saf. 2014;23(4):290-298. doi:10.1136/bmjqs-2013-001862

6. DelliFraine JL, Langabeer JR, Nembhard IM. Assessing the evidence of Six Sigma and Lean in the health care industry. Qual Manage Healthc. 2010;19(3):211-225. doi:10.1097/QMH.0b013e3181eb140e

7. Greenfield D, Braithwaite J. Developing the Evidence Base for Accreditation of Healthcare Organisations: A Call for Transparency and Innovation. BMJ Publishing Group Ltd; 2009.

8. Lovern E. Accreditation gains attention. Mod Healthc. 2000;30(47):46.

9. World Health Organisation (WHO). Quality and accreditation in health care services: a global review; 2003. cited 2003 Available from: http://www. who.int/hrh/documents/en/quality_accreditation.pdf. Accessed February 15, 2022.

10. Al-Awa B, Al Mazrooa A, Rayes O, et al. Benchmarking the post-accreditation patient safety culture at King Abdulaziz University Hospital. Ann Saudi Med. 2012;32(2):143-150. doi:10.5144/0256-4947.2012.143

11. The Saudi Central Board for Accreditation of Healthcare Institutions (CBAHI). National standards for hospitals; 2015. [cited 2015. Available from: http://www.cbahi.org/apps/en/accreditation/hospital-accreditation-program.aspx. Accessed February 15, 2022.

12. Qureshi AZ, Ullah S, Ullah R. The trend of hospital accreditation in the Kingdom of Saudi Arabia. Saudi Med J. 2012;33(12):1350-1351.

13. Jaafaripooyan E, Agrizzi D, Akbari-Haghighi F. Healthcare accreditation systems: further perspectives on performance measures. Int $J$ Qual Health Care. 2011;23(6):645-656. doi:10.1093/intqhe/mzr063

14. Al Shammari M, Al Habib S, Al Shubrami D, Al Rashidi M. Impact of hospital'accreditation on patient safety in Hail city, Saudi Arabia: nurses' perspective. J Nurs Health Sci. 2015;4(1):51-55.

15. Abolfotouh M, AlKelya M, AbuKhalid N, Salam M, Alamry A. Nursing perception towards impact of JCI accreditation and quality of care in a tertiary care hospital, Central Saudi Arabia. Int J Med Sci. 2014;47:1447-1460.

16. Garvey C, Cook J, Wiltsher C, Whitley S. Radiology accreditation—towards a safer quality service. Clin Radiol. 2009;64(9):853-856. doi:10.1016/ j.crad.2009.04.003

17. Kruskal JB, Eisenberg R, Sosna J, Yam CS, Kruskal JD, Boiselle PM. Quality improvement in radiology: basic principles and tools required to achieve success. Radiographics. 2011;31(6):1499-1509. doi:10.1148/rg.316115501

18. The American College of Radiology (ACR). Spotlight on accreditation; 2021. Available from: https://www.acr.org/Practice-Management-QualityInformatics/Quality-Care-News/Newsletter/Quality-and-Safety-eNews-December-2021/Spotlight-on-Accreditation. Accessed February 15, 2022.

19. Hogan H, Basnett I, McKee M. Consultants' attitudes to clinical governance: barriers and incentives to engagement. Public Health. 2007;121 (8):614-622. doi:10.1016/j.puhe.2006.12.013

20. Johnson K. Reducing unnecessary skull radiographs in children: a multidisciplinary audit. Clin Radiol. 2004;59(7):616-620. doi:10.1016/j. crad.2003.11.019

21. Institutions SCBfAoH. Primary Healthcare Standards; 2018. Available from: https://portal.cbahi.gov.sa/english/accreditation-programs/primaryhealthcare-center-accreditation-program. Accessed January 25, 2022.

22. Human resources and social development HRaS. Statistics and information 2022. Available from: https://hrsd.gov.sa/en/page/statistics-andinformation. Accessed February 15, 2022.

23. Raosoft. Sample size calculator by Raosoft; 2004. Available from: http://www.raosoft.com/samplesize.html. Accessed January $25,2022$.

24. Bornstein MH, Jager J, Putnick DL. Sampling in developmental science: situations, shortcomings, solutions, and standards. Develop Rev. 2013;33 (4):357-370. doi:10.1016/j.dr.2013.08.003

25. El-Jardali F, Jamal D, Dimassi H, Ammar W, Tchaghchaghian V. The impact of hospital accreditation on quality of care: perception of Lebanese nurses. Int J Qual Health Care. 2008;20(5):363-371. doi:10.1093/intqhe/mzn023

26. El-Jardali F, Hemadeh R, Jaafar M, et al. The impact of accreditation of primary healthcare centers: successes, challenges and policy implications as perceived by healthcare providers and directors in Lebanon. BMC Health Serv Res. 2014;14(1):1-10. doi:10.1186/1472-6963-14-86

27. Algahtani H, Aldarmahi A, Manlangit JJr, Shirah B. Perception of hospital accreditation among health professionals in Saudi Arabia. Ann Saudi Med. 2017;37(4):326-332. doi:10.5144/0256-4947.2017.326

28. Pomey M-P, Lemieux-Charles L, Champagne F, Angus D, Shabah A, Contandriopoulos A-P. Does accreditation stimulate change? A study of the impact of the accreditation process on Canadian healthcare organizations. Implementation Sci. 2010;5(1):1-14. doi:10.1186/1748-5908-5-31

29. Fairbrother G, Gleeson M. EQuIP accreditation: feedback from a Sydney teaching hospital. Austr Health Rev. 2000;23(1):153-162. doi:10.1071/ AH000153

30. Shortell SM, O'Brien JL, Carman JM, et al. Assessing the impact of continuous quality improvement/total quality management: concept versus implementation. Health Serv Res. 1995;30(2):377.

31. Devkaran S, O'Farrell PN. The impact of hospital accreditation on quality measures: an interrupted time series analysis. BMC Health Serv Res. 2015;15(1):1-14. doi:10.1186/s12913-015-0784-5

32. Mosadeghrad AM. Essentials of total quality management: a meta-analysis. Int J Health Care Qual Assur. 2014;27: 544.

33. Forsetlund L, Bjørndal A, Rashidian A, et al. Continuing education meetings and workshops: effects on professional practice and health care outcomes. Cochrane Database Syst Rev. 2009;2(2): CD003030.

34. Nekoei-Moghadam M, Amiresmaili M, Iranemansh M, Iranmanesh M. Hospital accreditation in Iran: a qualitative case study of Kerman hospitals. Int $J$ Health Plann Manage. 2018;33(2):426-433. doi:10.1002/hpm.2480

35. Reisi N, Raeissi P, Sokhanvar M, Kakemam E. The impact of accreditation on nurses' perceptions of quality of care in Iran and its barriers and facilitators. Int J Health Plann Manage. 2019;34(1):e230-e40. doi:10.1002/hpm.2642 
36. Wagner SE. Staff retention: from "satisfied" to "engaged". Nurs Manage. 2006;37(3):24-29. doi:10.1097/00006247-200603000-00007

37. Chandra A. Why do nurses leave and what can health organizations do to retain them? Hosp Top. 2003;81(3):33-36.

\section{Publish your work in this journal}

The Journal of Multidisciplinary Healthcare is an international, peer-reviewed open-access journal that aims to represent and publish research in healthcare areas delivered by practitioners of different disciplines. This includes studies and reviews conducted by multidisciplinary teams as well as research which evaluates the results or conduct of such teams or healthcare processes in general. The journal covers a very wide range of areas and welcomes submissions from practitioners at all levels, from all over the world. The manuscript management system is completely online and includes a very quick and fair peer-review system. Visit http://www.dovepress.com/testimonials.php to read real quotes from published authors.

Submit your manuscript here: https://www.dovepress.com/journal-of-inflammation-research-journal 